\title{
JUURNAL.RU
}

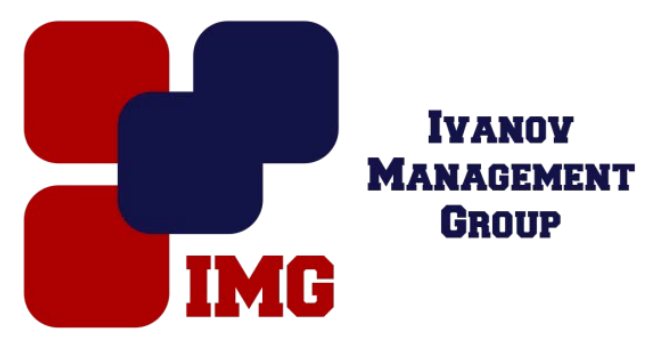

Закирничная М.М., Абдулганиева О.Р., Юдичева Д.А. ФГБОУ ВО Уфимский государственный нефтяной технический университет Уфа, Россия

doi: 10.18411/lj-31-10-2016-2-05

idsp 000001:lj-31-10-2016-2-05

\section{Возможность установления предельного состояния металла оборудования нефтегазопереработки с использованием акустико-эмиссионного контроля}

\section{Аннотация}

При проектировании оборудования важно не только получить надежную конструкцию, но при этом рационализироватьрасход конструкционных материалов.Использование метода предельных состояний при проектировании оборудования позволяет получить более экономичную конструкцию по сравнению с расчетом по методу допускаемых напряжений. В качестве предельной нагрузки в данном случае рассматривается момент образования трещины, который фиксируется с помощью акустико-эмиссионного прибора.

Ключевые слова: предельное состояние, расчет на прочность,допускаемое напряжение, метод акустической эмиссии.

Основной задачей расчета оборудования является обеспечение ее прочности. При оценке прочности оборудования по существующим нормативнотехническим документам используется расчет по допускаемым напряжениям. Сущностьрасчета по допускаемым напряжениямсостоит в том, что размеры конструкции назначаются из условия, чтобы действующие в них напряжения не превышали допускаемых напряжений. При этом в расчете используется коэффициент запаса прочности, величина которого зависит от многих факторов и который зачастую приводит к перерасходу материала для изготовления конструкций. Снижение массы конструкции без ущерба для eе 
работоспособности возможно при использовании метода предельных состояний[1]. При расчете поэтому методуосновным фактором является то, что за время эксплуатации сооружения не должно наступить ни одно из недопустимых предельных состояний. При этом можно получить более экономичную конструкцию без опасности ее преждевременного разрушения.

В основе метода предельных состояний лежит идея отказа от детального анализа всех состояний конструкции, кроме предельных, по отношению к которым и формулируются расчетные требования к объекту [2].В настоящее время различают три группы предельных состояний:

- первое предельное состояние - по несущей способности (прочности, устойчивости и выносливости - при переменны напряжениях);

- второе предельное состояние - по развитию чрезмерных деформаций (прогибов, перекосов и др.);

- третье предельное состояние - по образованию или раскрытию трещин.

При достижении предельного состояния трещины в оборудовании появляются и раскрываются до такой величины, при которой дальнейшая эксплуатация становится невозможной вследствие потери требуемой герметичности. Соответственно, для ответственных конструкций возникает необходимость определений значений напряжений, при которых дефект достигнет своего предельного размера.

В настоящее время перспективным методом исследования формирования несплошностей в материалах в процессе нагружения является метод акустической эмиссии, так регистрация акустико-эмиссионных сигналов позволяет в процессе эксперимента определить момент образования трещины [3]. Метод акустической эмиссии основан на регистрации звуковых сигналов, которые излучает материал в результате внутренней динамической локальной перестройки его структуры[4]. Метод позволяет в реальном времени по сигналам эмиссии наблюдать за поведением материала при нагружении. При малых скоростях деформации образца возбуждаемая эмиссия сравнима с фоновым шумом, но по мере роста скорости деформации число сигналов и их амплитуды возрастают, что связано с развитием трещины.В момент, когда сигналы энергии импульсов акустической эмиссии резко снижаются, 
нагружениедолжно прекратиться, так как сделано предположение, что резкий спад энергии должен соответствовать моменту образования дефекта критического размера.

Для подтверждения экспериментальных результатов необходимо изучение поверхности разрушения. Исследования можно проводить без специальной подготовки методом фрактографического анализа растровым электронным микроскопом. Исследованиефрактограммоднократного разрушения дает возможность определить его последовательность. Для изломов кратковременного однократного статического нагружения характерно вязкое или хрупкое разрушение. Вид разрушения зависит от многих факторов: состава металла, его структурного состояния, условий нагружения и температуры. В действительности в металлах не бывает ни чисто вязкого, ни чисто хрупкого разрушения. При вязком разрушении процесс распространения трещины происходит относительно медленно. Такие трещины часто характеризуют термином «стабильные» [5]. В этом случае материал сопротивляется дальнейшему развитию трещины, если только напряжение не увеличивается. Кроме того, визуально наблюдаются крупномасштабные деформации на поверхности разрушения в виде полос кручения и раздира. В случае же хрупкого разрушения, напротив, трещина распространяется очень быстро без каких- либо заметных пластических деформаций. Трещину в этом случае характеризуют как неустойчивую, а развитие трещины после того, как она возникла, происходит самопроизвольно без увеличения приложенного напряжения.

Использование метода предельных состояний позволяет уменьшить массу конструкций, делая ее более экономичной без опасности преждевременного разрушения. Одним из предельных состояний является недопущение образования трещин. Методом акустической эмиссии можно определить момент образования трещины, а фрактографический анализ позволяет подтвердить экспериментальные данные. 


\section{Литература}

1. Закирничная М.М.Особенности определения критерия предельного состояния для углеродистых и низколегированных сталей/Закирничная М.М.,Закирьянова А.Б.,Грешнов В.М // Электронный научный журнал «Нефтегазовое дело»,2012. - $\quad$ №6.- $\quad$ C.419-424.URL: http://ogbus.ru/authors/Zakirnichnaya/Zakirnichnaya_4.pdf

2. ГольденблатИ.И. Основные положения метода расчета строительных конструкций по расчетным предельным состояниям и нагрузкам / И.И. Гольденблат. Строительные нормы и правила. Часть 2 «Нормы строительного проектирования». - М., 1955. - 640с.

3. Закирьянова А.Б. Результаты использования акустико-эмиссионного контроля при испытании на растяжение образцов из стали 20/А.Б. Закирьянова,М.М.Закирничная// В сборнике: 63-я научно-техническая конференция студентов, аспирантов и молодых ученых УГНТУ. - Уфа: изд-во УГНТУ, 2012. - С. 262-263.

4. Оглезнева Л.А. Акустические методы контроля и диагностики. Часть II: учебное пособие / Л.А. Оглезнева, А.Н. Калиниченко. - Томск: Изд-во Томского политехнического университета, 2009. - 292 с.

5. Каллистер У. Материаловедение: от технологии к применению (металлы, керамика, полимеры) /Каллистер У., Ритвич Д.- Спб.: Научные основы и технологии, 2011. - 896 с. 